\title{
Formats of Classroom Talk for Integrating Everyday and Scientific Discourse: Replacement, Interweaving, Contextual Privileging and Pastiche
}

\author{
Peter Renshaw \\ School of Education, The University of Queensland, Australia
}

Raymond A. J. Brown

School of Education \& Professional Studies, Griffith University, Australia

In this paper we identify four formats of classroom talk for integrating everyday and scientific discourse - replacement, interweaving, contextual privileging and pastiche. In the replacement format, progress in understanding is gauged by the extent to which scientific representations replace the more concrete and everyday representations in students' talking and thinking. Research by Ballenger (1997) on Haitian children's engagement in classroom science talks illustrates the interweaving format. The classroom science talks interweaved scientific perspectives and concepts with issues of morality and identity raised by students. Wistedt and Martinsson (1996) provide evidence for a contextual privileging format. They identified different voices in children's discussions on mathematics topics - the everyday voice of practical reasoning, the voice of conventional schooling and the mathematical voice per se - the specific context of talk determined which voice was given precedence. Through our research we have identified the pastiche format of classroom talk. Pastiche refers to the process of compiling multiple representations of a concept for consideration by others. Greater articulation of the ways that everyday and scientific talk can be integrated extends existing research on Vygotsky's theory of learning and identifies styles of classroom talk for enhancing student inquiry and knowledge co-construction.

doi: $10.2167 /$ le 710.0

Keywords: classroom talk, Vygotsky, Bakhtin, collective argumentation, pastiche, exploratory talk

\section{Introduction}

Contemporary research has continued to explore the relationship between 'talking' and 'thinking' that was originally proposed by Vygotsky (1987) as fundamental to the development of higher mental processes. Of particular significance is his proposal of the metaphor of the intertwining of everyday and scientific concepts as the process upon which more abstract and general understanding emerges (John-Steiner et al., 1998). Intertwining is regarded as a dynamic and interactive process that occurs as partners engage in joint tasks, endeavouring to link their lived experiences of the world to established cultural 
frameworks such as those represented in school curricula. Recently, researchers have proposed typologies of talk (Mercer, 1995, 2000) and various formats of dialogue (Burbules, 1993; Renshaw, 2004) in order to identify the characteristics of classroom talk that engage students in co-reasoning about complex concepts and that build connections between students' life-worlds and that of the school curriculum (Ballenger, 1997). In this paper we use the existing research literature and our own empirical studies to identify four formats of classroom talk where 'everyday' and 'scientific' concepts are brought together and intertwined in different ways - replacement, interweaving, contextual privileging and pastiche. We have adopted the terminology of other classroom researchers in using the term 'formats' to describe recurrent patterns of classroom talk between teachers and students and amongst students themselves (Cazden, 1988; Crago et al., 1997; Heap, 1985; Mehan, 1979). Our typology provides insight into how understanding develops through the process of talking about 'everyday' and 'scientific' concepts, and it provides a guide to teachers on how different formats of talk can usefully be deployed to facilitate particular pedagogical goals. While grounded on Vygotsky's original distinction between everyday and scientific concepts, we also draw upon Bakhtin's (1981) theory of language genres to analyse how children adopt different voices and, at times, shift between a variety of speaking positions in proposing ideas and arguing for their acceptance by peers and the teacher.

\section{Vygotsky's distinction between everyday and scientific concepts}

Like many of his key theoretical terms, Vygotsky worked and reworked the distinction between everyday and scientific concepts in a number of different chapters and articles (Minick, 1987). In Chapter 5, 'Thinking and Speech',Vygotsky (1987) reported experimental research on children's concepts in an attempt to unravel the natural, spontaneous line of development from the cultural line. The distinction between the spontaneous and the cultural is similar to others that he explored such as everyday concepts and scientific concepts, or rudimentary mental functions and higher mental functions. These distinctions were proposed and examined by Vygotsky to demonstrate that progress in thinking involved the transformation of the everyday, spontaneous and elementary processes by the cultural, abstract and higher processes. A step along the path of transformation was the emergence of the pseudo-concept, which stands between the everyday and the scientific conceptual forms. The pseudoconcept was regarded by Vygotsky as creating the possibility of productive dialogue between children (as cultural novices) and adults (as cultural experts). During interaction with adults, children were observed to use everyday words and phrases in a manner that appeared to overlap with adult usage, but in fact Vygotsky claimed that adults understood the words in a more abstract and general manner than children. This has important pedagogical implications because the appearance of a substantially overlapping set of meanings enables the adult and child to collaborate in joint activities, where the adult acted as if the child were further advanced in understanding than actually was the case. Such misunderstanding is productive because it reveals to children the underlying structure of their thinking and creates conditions for a more deliberate and reflective application of concepts. 
In Chapter 6, 'Thinking and Speech', Vygotsky (1987) further explored how understanding emerges through social interaction and dialogue. As in Chapter 5 , he described conceptual development as an interaction between natural, spontaneous concepts and the organised systems of concepts referred to as 'scientific' concepts. He argued that scientific concepts do not simply replace spontaneous concepts during the process of development. He used the metaphor of growth to describe the reciprocal influence of concepts-scientific concepts growing downward through spontaneous concepts, while spontaneous concepts grow upward through scientific concepts. Vygotsky argued that spontaneous concepts provide the necessary, but not sufficient, conditions for progress toward more powerful forms of thinking. He saw culture, in this case the systems of abstract concepts incorporated in school curriculum, as being the driving force in development. However, scientific concepts presented to children in general and abstract terms without connection to their concrete, empirical and personal experience must remain empty formalism. On the other hand, spontaneous concepts remain limited in their application and generality without being connected to more systematised concepts. Thus, the education of children requires the creation of social contexts of collaborative thinking, where everyday and scientific concepts are brought together (Kozulin, 1990).

\section{Examples of pedagogy based on the everyday-scientific distinction}

The formats of classroom talk that we propose here are aligned with different pedagogies. For example, Davydov (1975a, 1975b) developed a mathematics curriculum for young children, which was designed to move them beyond their initial everyday and concrete concepts of quantitative relations (relations of equality, more than and less than) to an abstract representation that employed algebraic symbols $(a=b ; a>b ; a<c)$. Davydov's curriculum began with children's existing words for comparisons of quantity (same, big, small), but rapid progression in the level of abstraction and generalisation was required of children so that eventually under teacher guidance, they were working with algebraic formulas and more precise comparative language (equal in length, longer than, shorter than).

Another example of a pedagogical approach designed to integrate everyday and scientific concepts comes from the work of Newman et al. (1989) who argued that creating conditions for conceptual change necessarily required a divergence in understandings. They elaborated their case on the basis of the pervasive indeterminacy of the meaning of speech during conversations between adults and children. Any word or utterance has a number of meanings, depending not only on the relative levels of development of the communicative partners (as Vygotsky had argued) but also on differences in personal experiences or interpretations of the present situation. To coordinate their actions and regulate joint attention, the child and adult necessarily speak and act in ways that are responsive to the words and actions of the other. In such conversational dialogues, adults will expand the contributions of children, paraphrase, reinterpret and substitute more general concepts for the children's everyday forms of speaking and acting. In this manner, conversing with adults enables children to enter into new more abstract and general ways of speaking about, and acting 
towards objects - that is, it opens up a zone of proximal development (zpd). To encapsulate their view of such interaction, Newman et al. (1989) describe the partners as entering into 'a strategic fiction' - a space of productive misunderstanding where children are assisted to transform their pseudo-concepts by the words and actions of more advanced participants. This cultural knowledge notion of the zpd, i.e. the distance between the cultural knowledge available within an instructional context and the everyday knowledge and experience of a learner, focuses on the classroom as the site of knowledge construction and reconstruction.

Although there remain difficulties in specifying with any precision the distinction between the terms 'everyday' and 'scientific' (Zack, 1999), the pedagogical projects reviewed here so far (and others, e.g. Lampert, 1990, 1998; Tharp \& Gallimore, 1988) provide evidence that progress in thinking involves some form of integration between students' everyday experiences and concerns, with the cultural and disciplinary knowledge provided within educational institutions. Also, the intertwining metaphor used by Vygotsky requires further differentiation and articulation. To contribute to clarifying this latter issue, in this paper we identify four ways in which everyday and scientific discourses have been related in studies of classroom talk: (1) in terms of a replacement format (Davydov, 1975a, 1975b); (2) as an interweaving format (Ballenger, 1997); (3) in terms of a contextual privileging format (Wistedt \& Martinsson, 1996); and (4) in terms of a pastiche format (Renshaw \& Brown, 1998). Our purpose is not to choose between them, but rather to explicate the characteristics of the formats and to explore the implications of these formats for the role of teachers as 'discursive guides' in children's learning.

\section{Replacement Format}

The replacement format emphasises the importance of adopting precise terms and acting within the ground rules of particular discourse genres. Initially, there is attention and space given to the perspectives, words and values that children bring with them into the classroom talk, but these provide a temporary bridge into new forms of speaking and thinking. The aforementioned Davydov teaching experiment provides evidence of the replacement format of classroom talk. Working in the field of mathematics teaching and learning, Davydov conceived the subject matter of mathematics as basically dealing with abstract structures that needed to be applied to concrete situations. The extent of student involvement in mathematics was to be seen in the extent to which students used the symbolic systems of mathematics to organise and solve quantitative and spatial problems (Van Oers, 2001). In Davydov's study, the key pedagogical strategy was teacher questioning. Children were guided by leading questions, e.g. 'What does that mean - heavier?' (Davydov, 1975: 150), to use speech to conceptualise their experiences in more abstract and precise terms. Children preferred the comparatives (thicker, larger, heavier or the same) to the more abstract 'less than in width', or 'more than in length', 'equal in weight'. In later episodes of the teaching experiment the children began to adopt the more abstract speech introduced by the teacher, as illustrated in the following dialogue. 


\section{Extract 1}

Teacher: We won't help him for the time being! Now think.

Misha V: (after a short pause) The letters tell me about the length of the pencils - this one and this one.

Teacher: Is that all? If the letters tell about the length, then I'll take a pencil of this length - this is A, and one of this length - this is B: What I get is that A is less than B.

Pupils: You can't take those - then you have a different formula.

Misha V: We have an equality - there is an equal sign there. We have to take pencils of equal length and then it's right.

Teacher: Then what tells about the equality itself?

Pupils: The symbol between the letters - the whole formula.

Teacher: Now I'm changing the symbol in my formula to read A is less than B. Can you find objects to show what this means?

(Davydov, 1975b: 151)

The teacher began with the words that the children brought with them into the classroom, and she assisted them by leading questions to employ other expressions - more precise, more abstract and more general phrases - that could be used to replace their everyday words. In turn, these abstract phrases were rerepresented as symbols in mathematical equations $(=,<$ and $>)$. The pedagogical process in the replacement format, therefore, requires children to work within a system of signs and symbols with its own logic and set of meanings, rather than to oscillate between everyday experiences and scientific abstractions. Within this pedagogical process, it is the voice of the teacher that guides and provides direction to the talk. It is the teacher who focuses on the mathematical practices of 'symbolising' and 'comparing', and on mathematical goals/values such as being 'challenged' and showing 'persistence'. ('We won't help him for the time being! Now think.') Even the abstract structures dealing with equivalence and inequality are introduced by the teacher. As such, the efficacy of the replacement format is dependant on the level of teacher expertise in the knowledge domain.

\section{Interweaving Format}

Ballenger's research (1997) on science talk in the primary classroom exemplifies the interweaving model. Ballenger's research was conducted in an upper primary science classroom where Haitian students from poor families were invited to participate in 'science talks' - whole class discussions based on everyday experiences with phenomena such as skin colour, mould and so on. The choice of topic was crucial in enabling children to draw on experiences, observations, values and opinions that were derived from outside of the school and classroom. Students were encouraged to see these everyday experiences as relevant to the class discussions. Given support by the teacher to speak in their familiar Haitian creole and encouraged to talk broadly about the issues, the students introduced concerns that were not strictly scientific.

In the discussion of mould, for example, some students spoke passionately about issues such as personal cleanliness, morality and poverty (see Transcript 1 , 
Appendix). In the following quotation, Manuelle introduces moral concerns into the classroom discourse about the growth of mould. She proposes that mould grows because people '... don't care, they don't clean.' When other students claim that all toilets grow mould, Manuelle disagrees strongly, 'OK. What I told you, I told you, MY TOILET at MY HOUSE doesn't have mould because I CLEAN it.' Other students continue to dispute Manuelle's claim, and finally Marc proposes that 'we ought to do an experiment.' The moral and the scientific perspectives are both present in this discussion. Manuelle is intent on upholding her cleanliness and moral status. Marc and some other students are beginning to talk within a set of scientific assumptions - they make general claims (all toilets have mould) and appeal to empirical evidence and experiments. Other students appear ambiguously placed in terms of their perspective in the talk. Joanne, for example, in representing herself as a clean-living person ('Monday Tuesday, Wednesday, we usually clean the bathroom'), includes reference to Clorox bleach that is necessary to get all the mould out. She is beginning to consider the conditions and substances that might enhance or hinder the growth of mould, so a supportive teacher could readily scaffold her adoption of scientific discourse in this episode.

So what did the students learn from talking outside the strict realm of science? Ballenger suggests that students learned to populate scientific discourse with their own voices, i.e. they learned to weave together scientific and everyday discourse into a local hybrid that reflected their specific circumstances. Ballenger notes that this mirrors, in many ways, the actual practice of the scientific community where personal values, interests and concerns are present at various stages of the scientific work but are obscured in the final product.

The interweaving of different perspectives in this classroom occurred at two levels. First it occurred at a level where children's inventive ideas (e.g. that 'Toilets make mould!') were interwoven with the conventions of scientific inquiry (theorising, hypothesising and testing the conditions that support mould). Second, it occurred at a more personal level where children's individual approaches to doing science were interwoven with the representational systems and inquiring dispositions and values of the scientific community. As such, interweaving different perspectives in classroom talk appears productive in enabling the students to not only appreciate the relevance of the 'science' in understanding certain everyday experiences such as their observations of mould in damp places or its association with decaying food, but also in facilitating their consideration of the conditions and dispositions that might enhance their growth as scientists. The moral concerns of Manuelle do not have to be marginalised. Rather it seems that the metaphor of reciprocal growth of everyday and scientific concepts aptly captures the hybrid type of talk reported by Ballenger.

The importance of interweaving talk for bringing students into the 'progressive' discourse of a scientific community is supported by Bereiter (1994) who proposed four 'quasi-moral commitments' that serve to distinguish scientific discourse from other disciplinary discourses: (1) mutual understanding - a commitment to work towards a common understanding; (2) empirical testability - a commitment to frame ideas in ways that allow evidence to be considered; (3) expansion - a commitment to expand the conversation; and (4) openness - a commitment to allow beliefs to be subjected to criticism. In terms of 
connecting student inquiry with learning science, practices such as those proposed by Bereiter, emphasise the role that classroom discourse can play in supporting students' conceptual development. From strictly scientific perspective, it can be said that the Haitian children studied by Ballenger learned a great deal about the language and practice of science. One student when asked what he had learned, laughed and answered in Creole, 'It's not what I learned. I have a question to ask you.' He then asked, 'How did the mould manage to become green, it became yellow, white, black, brown?' (Ballenger, 1997: 10). These comments reveal his appropriation of the scientific disposition to inquire and question rather than to seek closure.

\section{Contextual Privileging Format}

Wistedt and Martinsson's (1996) study of children's 'discovery of infinity' during a session of peer group interaction provides evidence for a contextual privileging process. While similar to the replacement format in marginalising certain types of discourse, the contextual privileging format highlights the situational and context-specific grounds for privileging one type of discourse over another. It is not that 'scientific' concepts are proposed as qualitatively better in some general sense. Rather, certain ways of speaking and thinking are chosen over other possibilities on the grounds of appropriateness to the particular setting with its specific set of ground rules for participation. This relates to Van Oers' (1998) concept of 'contextualising' where the actions to be performed are not privileged by a predetermined abstract structure as in the case of the replacement format, but are privileged in a process of discursive negotiation occurring between class participants. According to Van Oers (2001), the context of an activity is not determined primarily by the characteristics of the situation of the activity (home or school), but depends on how a situation is interpreted and produced by those carrying out the activity. Contextualising is the process of context making as participants interact deploying mediating tools, speech and artefacts within a given situation. In this process, an agreed sense emerges of what can be said or done, what cannot be said or done, and what alternatives can be considered. In conventional classrooms, engagement in most school subjects has explicit ground rules for participation based on the I-R-E script where the teacher controls the direction and type of talk (Lemke, 1990; Mehan, 1979). However, in the study reported by Wistedt and Martinsson (1996), the students were investigating a problem in small groups, and the talk was more unpredictable and contested and the process of contextualising more visible as they debated the appropriate way to engage in the activity. As elaborated in the following, the students' talk revealed how a particular context came to be privileged.

\section{Privileging the voice of mathematics over school and practical voices}

These 11-year-old students were working on the problem of dividing 100 into three equal parts and expressing their answer as a decimal. Different voices were identified in children's discussions - including the everyday voice of practical reasoning - 'But why do we have to make three bookstands. He just needs two, one on each side of the books.' This particular student attempted to redefine 
the problem so that it could be resolved practically, but his partner reasserted the voice of schooling by saying, 'Yes, but now they've made it in this weird way so we will have to solve it as it is, won't we.' The contest between different voices was quite explicit - 'so we will have to solve it as it is, won't we.' In this direct way, the practical voice was marginalised and the students turned their attention back to the task - now interpreted as a school task where the major concern was to produce an acceptable answer for the teacher. However, there is a further shift in stance to a mathematical perspective per se, as the students begin exploring and speculating about the nature and limitations of the number system. Students realised during their discussion that certain quantities such as one third could not be exactly expressed as a decimal - 'You can go on forever. It will never come out even. But the more 03's you write, the closer you will get.'

In Wistedt and Martinsson's study, therefore, progress in understanding depended on the introduction and adoption of the mathematical voice as more appropriate in this context than the practical everyday voice. If the children had returned to the practical task of dividing a piece of wood into three, their mathematical speculations about the limitations of the decimal system would have been irrelevant. On the other hand, an expert mathematics teacher could easily imagine new challenges within the field of mathematics to extend their emerging deep understanding of different ways to represent certain quantities and lengths. The important aspect of the interaction between the children was the use of context-based arguments. So, when one student says, 'Yes, but now they've made it in this weird way so we will have to solve it as it is, won't we', she is not dismissing the other student's suggestion as simply incorrect but as inappropriate in the present institutional context of schooling.

\section{'If you were teaching someone who didn't know anything about this. . .'}

An example of contextual privileging, drawn from our classroom observations, is provided in the following example where Chris, Liam and Robyn are presenting to their classmates a solution to a typical school mathematics problem, 'At the end of the week I have found that I have spent $30 \%$ of my weekly wage on food, $2 / 5$ of my weekly wage on rent, and 0.2 of my weekly wage on personal items. If I earn a hundred dollars a week, how much money will I have left?'

\section{Extract 2}

Liam: And we ... twenty percent ... um, point two for the personal items, and we came to that, um, twenty percent [writes in $20 \%$ so the line reads $0.2=20 \%$ ] $\ldots$. And then we added, we plused the thirty percent, forty and twenty percent which came to ninety.

Kerri: $\quad H o w$ did you get twenty percent from point two?

Chris: Um, how do we, well we converted point two to, um. We just wrote in our pad zero point two zero, and we just knew, like automatically that, you know. Like two in decimal, uh, point two in decimal ... [writes 0.20 on the blackboard]. 
Katie: Um, not that ten isn't the number [answer], but where you put the point two equals twenty percent, you should have put the zero after it [meaning 0.20 rather than 0.2 ], so that it's easier to understand.

Robyn: We did.

Katie: Where?

Chris: Well you see we don't actually have it, but ...

Katie: But if you were trying to teach someone...

Chris: No, see what we're doing is we're just copying straight off the sheet [their problem sheet].

Teacher: What Katie is saying ...

Katie: I said that ...

Chris: $\quad$ But I understand what you are saying ...

Teacher: [To the group] No, you're sort of talking over the top of her [Katie]. Let her express her point of view and then the class can decide. Katie can you express your point of view please.

Katie: $\quad$ Yes. If you were teaching someone who didn't know anything about this and ... the easiest way to express the point two would be, twenty percent, would be to put the zero after it. Because then it would be twenty hundredths because the point two doesn't really mean anything when you say it. So it would be better to put twenty-hundredths.

Different voices are deployed by the children in the above extract. Chris says, 'No, see what we're doing is we're just copying straight off (their problem sheet).' Chris attempts to define the task as a routine school task where following teacher directions and copying are paramount. When Katie responds - 'the easiest way to express the point two would be, twenty percent, would be to put the zero after it. Because then it would be twenty hundredths because the point two doesn't really mean anything when you say it. . ' - she draws upon a developing understanding of the mathematical voice that privileges efficiency ('the easiest way to express the point two would be...') and clarity ('the point two doesn't really mean anything when you say it'). She demonstrates a particular sensitivity to the context of their talk by her comment, 'If you were teaching someone who didn't know anything about this...' Katie's imagination of a hypothetical audience (if you were teaching... ) enters as a crucial consideration in her judgement of the adequacy of Chris' group's presentation. The important aspect of the interaction between the participants, therefore, was not the use of symbolic representations per se, but the use of context-based arguments. Katie is not dismissing the group's solution as being incorrect, but as being inappropriate in the present mathematical context of classroom discourse. This is a sophisticated stance that entails judging the worth of an idea on its relevance to a particular setting.

\section{Pastiche Format}

The pastiche format of classroom discourse highlights multiple representations of concepts and multivocality in the way students talk about the concepts. 
Drawing on the insights of Bakhtin (1981), we suggest that in any individual utterance, a number of voices can be heard - the voice of the particular person along with the traces of the voices of other community members who had previously employed those words to convey their own meanings. Difference, diversity or multivocality occurs not only between speech partners, but within individual utterances as speakers use the words and phrases of others to construct and convey an idea (Hirst \& Renshaw, 2004). Pastiche is, therefore, a format of talk that values multivocality within an individual utterance and across speakers. The pedagogy is not primarily focused on replacing one form of discourse with another but on eliciting and communicating diverse ways of thinking about and talking about concepts.

The illustration of the pastiche format is drawn from classroom-based research that we have conducted for a number of years (Brown, 1994, 1997, 2001; Brown $\&$ Renshaw, 1995, 1996). We have focused on how to reconstitute everyday classroom practices in the upper primary school using a sociocultural perspective as a tool, both to generate new practices and to critically reflect on change as it occurred. One strategy that we have used is 'collective argumentation', a small group process that is designed to extend the range of speaking opportunities available to students in the classroom. Collective argumentation consists of the following processes: represent the task or problem alone, compare representations within a small group of peers, explain and justify the various representations to each other in the small group, reach agreement within the group, and finally present the group's ideas and representations to the class to test their acceptance by the wider community of peers and the teacher.

Each step in collective argumentation challenges the students to adopt different speaking positions or voices. The initial speaking position is personal - 'My representation'. This step of representing alone is important for creating a diversity of possible approaches to the task. Students become aware that different task interpretations and emphases are commonplace and that fellow students can have quite different but equally adequate ways of considering the task. It should be recognised that the representations produced by the students even at this initial step of collective argumentation are not simple expressions of a personal voice. Each personal voice is already multivocal, since diverse experiences at home, at school and from the media will be drawn upon in constructing the representations. The small group processes that follow this individual work are designed to move students to an agreed representation (or set of representations) of the task. Here the speaking positions alternate between explaining or defending personal representations and moving towards a common view. There is a movement from 'my ideas' and 'your ideas' to 'our ideas'. In the process of collective argumentation, students are required to ensure that all members of their small group understand the common approach to the task. That is, each member of the group must have a sense of their shared authorship of the group's ideas. Finally at the last step of collective argumentation, where the groups present their ideas to the rest of the class, the students have the opportunity to explain their ideas to a broader audience. The speaking position here is similar to that of the teacher, affording the students both the status of 'expert' as well as the challenge to present and defend solutions to an audience of peers. 


\section{Explaining 'infinity' by deploying the pastiche format}

The emphasis in collective argumentation on comparing different representations, and forestalling judgement on the most adequate representation until everyone had a chance to explain and justify their ideas, has enabled the children to operate confidently with multiple perspectives. To illustrate, in one episode of collective argumentation, Angela was explaining her idea of infinity. Prior to Angela's presentation, a number of other groups had already presented their ideas on infinity to the whole class - these consisted of drawings of lines, spirals, circles and other closed geometric shapes which were meant to convey the idea of infinity as endless space and distance - with neither a beginning nor an end. Angela's presentation of her group's ideas begins by focusing on time, and she uses the image of a clock with a very large array of hands to convey the idea of infinite time.

\section{Extract 3}

Angela: We drew a clock and we had, um, about, an infinite number of handles, because time goes on for an infinity. That's how we represented that, because time goes on.

Teacher: I didn't understand that phrase, could you say it again please.

Angela: Well, we drew a clock and we had an infinite amount of handles, the little things that go around, because time never stops. It just keeps going around.

[Teacher clarified with Simon and Angela the term for the hands of the clock, and then Angela continued]

Angela: Time has no beginning and no end like numbers. And we had the dictionary meaning which says this - infinity has the state of being infinite, infinity of the universe, infinity of space, time, quantity - so infinite space, so, it's so that you can't describe it. Um, (infinite) mass is the concept of increasing (mass) without volume. So we thought that we would make a meaning of our own. So we thought that infinity means everlasting number, object and the universe. So infinity is an everlasting thing. [Teacher recalled the key ideas from Angela's presentation.]

Angela: Infinity can(not) be determined or explained over a vast amount or period of time, because it is an everlasting idea. And I made this up. I think the word infinity is similar to life. No one can fully explain it and just like infinity it has many definitions. We can't really explain life and we can't really explain the word infinity.

Angela's presentation to the class shows an explicit awareness that particular ideas are related to the stance or position of the speaker; notice how Angela uses 'we', 'I', 'you' and 'no-one' to signal her adoption of a series of different speaking positions. For example, she adopts four different stances: (1) the authoritative voice of the dictionary ('And we had the dictionary meaning which says this'); (2) the voice of her group ('so we thought that we would make a meaning of 
our own'); (3) a personal voice ('And I made this up. I think the word infinity is similar to life'); and (4) the generalised voice of an expert ('No one can fully explain it and just like infinity it has many definitions. We can't really explain life and we can't really explain the word infinity'). 'No one' and 'we' convey Angela's intention to speak authoritatively not on behalf of her small group, or personally, but generally on behalf of humankind.

Angela's presentation on behalf of her group provides a good model of the pastiche format - she 'pastes up' side by side for her audience to consider four representations of infinity. Each alternative is offered from a specific speaking position that is named by Angela as she shifts between different voices ('we,' ' $\mathrm{I}$,' 'you,' 'no-one'). Understanding is achieved by Angela as she collates the various features of the pastiche rather than privileging one aspect over another, or replacing one representation with another. Angela seemed satisfied that the collation of diverse alternative voices provided an acceptable basis for understanding the complex concept of 'infinity'.

\section{Explaining collective argumentation in the pastiche format}

Another episode from our research illustrates how the format of pastiche can emerge from teacher-student exchanges as well as from peer group interaction. Transcript 2 (see Appendix) contains the full extract of the talk between a student (Lisa) and a visiting teacher, who was interested in the notion of collective argumentation. In order to respond to the teacher's questions, the students had to raise their hands and wait to be selected. Lisa engaged in extended interaction with the teacher, deploying many different speaking positions or voices. The presentation of these positions begins with Lisa's response to the teacher's question, 'What is collective argumentation?' Lisa talks with an authoritative voice that might be found in a dictionary ('Collective argumentation is a form of doing mathematics that's new and probably improved'). By stating that collective argumentation is a form of doing mathematics, Lisa signals it as being one among the many ways of doing mathematics. She denotes a general class of activities related to doing mathematics of which collective argumentation is one-a new and probably improved one. This qualification 'probably improved' inserts a conditional judgment that invokes an empirical perspective. Thus, Lisa's initial voice is similar to a dictionary in the sense that it is quite formal and general.

Lisa's responses to other questions provide the context for her deployment of shifting voices or stances regarding collective argumentation. When asked 'How does collective argumentation differ from other ways of learning mathematics?' Lisa talks as if she is a professional teacher explaining her thinking by reference to different learning styles and their effectiveness ('Um, there seems to be three general ways of learning, um. One is by hearing it. You hear it and you can repeat it. It's good for like music. The other one is you see it, visual, and you can memorise it. The other is, like, touch, like, you write it [writes in the air with her hands']). In response to the question, 'What haven't you enjoyed about collective argumentation?' Lisa talks more personally as a student ('Um, the problems ... I know that some people are slower, but it's very difficult when you've only got one problem to solve and, you know, it might be the same type. 
Like, just say we're doing area. It might be a whole week of area problems, and you get a little sick of just doing area). Lisa's stance shifts here from that of a dictionary or a professional expert to that of a reflective, albeit a slightly superior student. At this moment Lisa does not speak for or on behalf of her classmates. Clearly it is Lisa's personal view, not everyone's view, and in particular not the view of the 'slower' classmates.

Lisa's talk in the class forum on collective argumentation is a good example of the pastiche format. In response to the teacher's questioning, she provides multiple representations of collective argumentation for consideration. Our complete analysis of Transcript 2 suggests the following representations: (1) a new and probably improved way of learning; (2) a local method of problem solving; (3) a multi-modal approach that has the potential to transform understanding; (4) an approach suited to slow learners, but that lacks task variety; (5) a communal practice that has the potential to improve social relationships; (6) a useful tool for dealing with problems in high school tests; and (7) a personal aspiration for the future of Australian schooling. Each alternative is offered from a specific speaking position that is deployed by Lisa as she shifts between different voices ('I', 'we,' 'us', 'you'). Like Angela (in explaining infinity), Lisa draws on various discourse communities and their distinct voices in exploring the multi-faceted meaning of collective argumentation.

\section{Implications}

The replacement format of classroom talk provides a view of learning as a process of transformation where more abstract and general concepts supersede more concrete and experiential concepts. The interweaving format provides a view of learning as a transformative process where the everyday and scientific forms of discourse grow together into a hybrid form of understanding. The contextual privileging format provides a view of learning as situated and contextualised. Certain ways of speaking and thinking are appropriate and privileged in particular contexts, rather than simply correct or incorrect, true or false. The pastiche format provides a view of learning as a process of adding cultural tools to an expanding repertoire of possibilities for action within specific situations. Together, these four formats of classroom talk provide a useful heuristic to begin conversations with teachers about how the everyday and the scientific can be integrated in different curriculum domains to promote students' understanding.

\section{Exploratory talk and the formats of talk}

Classroom talk has recently been described in terms of broad typologies, such as exploratory, cumulative and disputational talk (Mercer, 1995; Wegerif \& Scrimshaw, 1997). This analytical framework has been useful in identifying and articulating the kinds of talk related to particular learning outcomes (Wegerif et al., 1999). The four formats of classroom talk can be regarded as different instantiations of exploratory talk and a useful differentiation of that style of classroom talk. We suggest that exploratory talk can take on the characteristics of the replacement format as students rephrase ideas and adopt the language of the particular curriculum domain to express their thinking with each other. They may also talk in exploratory ways while connecting a variety of personal 
experiences with the topic at hand (interweaving), or debate with each other regarding how to proceed with a task or whether the evidence presented for an idea is relevant in this context (contextual privileging), or finally, they may propose a whole array of ideas as relevant and plausible ways to understand a topic and compare and contrast the ideas to appreciate how each adds to a complex understanding of the topic (pastiche).

\section{Conclusion}

The heuristic formats that we have articulated here provide teachers with a resource to design pedagogical spaces that invite greater participation by students in classroom activities and a greater sense of collective authorship of the knowledge and skills generated in classrooms. By describing different formats of classroom talk in some detail and comparing the role of the teacher across the four formats, we hope to enhance the effectiveness of educators in deploying classroom talk for deeper learning across curriculum domains. The differentiation of Vygotsky's generative metaphor of 'intertwining' into the four formats suggests that there are a variety of paths to deeper understanding, and different strategies can be deployed to assist students on their way. It is preferable to envisage educators deploying all the formats at different times and at different points on a learning journey. Recently, in studying effective forms of pedagogy in Singapore, Luke et al. (2005) used the metaphor of 'weaving' to capture the diverse practices that effective teachers used to assist deep learning. Teachers wove together into one classroom episode scaffolded learning, direct instruction, peer exploration, as well as moments of quiet study and reflection. We similarly suggest that within one classroom episode, a teacher might deploy paraphrasing strategies to extend students' vocabulary (replacement); might invite students to converse about their experiences at home or with friends that connect with a curriculum topic (interweaving); might challenge students to consider the kinds of arguments and evidence that hold sway in this discussion (contextual privileging); and might bring together for consideration a number of plausible representations of a concept and reflect on how the array of representations assists a deeper understanding of the topic (pastiche). Further research is needed on how 'disputational talk' mediates learning outcomes for students in classrooms. Some students deploy peer-directed talk about popular culture and peer activities outside the school to resist and reject aspects of school learning. Such talk reveals their interests and current investments and so might be regarded as revealing the 'everyday'. The challenge is to find ways to work with these interests and investments in the service of developing more powerful forms of cultural knowledge that increase the students' life chances.

\section{Correspondence}

Any correspondence should be directed to Professor Peter Renshaw, School of Education, The University of Queensland, St. Lucia Campus, 4072, Australia (p.renshaw@uq.edu.au). 


\section{References}

Bakhtin, M.M. (1981) The Dialogic Imagination: Four Essays (M. Holquist, ed. \& trans. and C. Emerson, trans.). Austin, TX: University of Texas Press.

Ballenger, C. (1997) Social identities, moral narratives, scientific argumentation: Science talk in a bilingual classroom. Language and Education 11 (1), 1-13.

Bereiter, C. (1994) Implications of postmodernism for science, or science as progressive discourse. Educational Psychologist 29 (1), 3-12.

Brown, R.A.J. (1994) Collective mathematical thinking in the primary classroom: A conceptual and empirical analysis within a sociocultural framework. Bachelor of Educational Studies (Hons.) thesis, University of Queensland, Brisbane, Australia.

Brown, R.A.J. (1997) 'You can't explain infinity!': Collective argumentation discourse across primary school subject domains. In M. Goos, K. Moni and J. Knight (eds) Scholars in Context: Prospects and Transitions (pp. 17-22). Brisbane: Post Pressed.

Brown, R.A.J. (2001) A sociocultural study of the emergence of a classroom community of practice. Unpublished PhD thesis, University of Queensland, Brisbane, Australia.

Brown, R.A.J. and Renshaw, P.D. (1995). Developing collective mathematical thinking within the primary classroom. In B. Atweh and S. Flavel (eds) Proceedings of the Eighteenth Annual Conference of the Mathematics Education Research Group of Australasia (MERGA) (pp. 128-134). Darwin: Mathematics Education Research Group of Australasia.

Brown, R.A.J. and Renshaw, P.D. (1996) Collective argumentation in the primary mathematics classroom: Towards a community of practice. In P.C. Clarkson (ed.) Technology in Mathematics Education: Proceedings of the Nineteenth Annual Conference of the Mathematics Education Research Group of Australasia (MERGA) (pp. 85-92). Melbourne: Mathematics Education Research Group of Australasia.

Burbules, N.C. (1993) Dialogue in Teaching: Theory and Practice. New York: Teachers College Press.

Burbules, N.C. and Rice, S. (1991) Dialogue across differences: Continuing the conversation. Harvard Educational Review 61 (4), 393-416.

Cazden, C.B. (1988) Classroom Discourse: The Language of Teaching and Learning. Portsmouth, NH: Heinemann.

Crago, M.B., Eriks-Brophy, A., Pesco, D. and McAlpine, L. (1997) Culturally based miscommunication in classroom interaction. Language, Speech and Hearing Services in Schools 28 (3), 245-254.

Davydov, V.V. (1975a) Logical and psychological problems of elementary mathematics as an academic subject. Soviet Studies in the Psychology of Learning and Teaching Mathematics 7, 55-108.

Davydov, V.V. (1975b) The psychological characteristics of the prenumerical period of mathematics instruction. Soviet Studies in the Psychology of Learning and Teaching Mathematics 7, 109-206.

Heap, J. (1985) Discourse in the production of classroom knowledge: Reading lessons. Curriculum Inquiry 15 (3), 245-279.

Hirst, E. W. and Renshaw, P. (2004) Diverse voices, dialogue and intercultural learning in a second language classroom. In J. van der Linden and P. Renshaw (eds) Dialogic Learning: Shifting Perspectives to Learning, Instruction and Teaching (pp. 87-108). Dordrecht: Kluwer Academic.

John-Steiner, V., Wardekker, W. and Mahn, H. (1998) Concepts, contexts and transformation : Scientific and everyday concepts revisited. Mind Culture and Activity 5 (2), 81-153.

Kozulin, A. (1990) Vygotsky's Psychology : A Biography of Ideas. Cambridge, MA: Harvard University Press.

Lampert, M. (1990) When the problem is not the question and the solution is not the answer: Mathematical knowing and teaching. American Educational Research Journal 27 (1), 29-63.

Lampert, M. (1998) Investigating teaching practice. In M. Lampert and M.L. Blunk (eds) Talking Mathematics in School: Studies of Teaching and Learning (pp. 153-162). Cambridge: Cambridge University Press. 
Lemke, J.L. (1990) Talking Science: Language, Learning, and Values. Norwood, NJ: Ablex.

Luke, A., Freebody, P., Shun, L. and Gopinathan, S. (2005) Towards research-based innovation and reform: Singapore schooling in transition. Asia Pacific Journal of Education $25(1), 5-28$.

Mehan, H. (1979) Learning Lessons: Social Organisation in the Classroom. Cambridge, MA: Harvard University Press.

Mercer, N. (1995) The Guided Construction of Knowledge: Talk Amongst Teachers and Learners. Clevedon: Multilingual Matters.

Mercer, N. (2000) Words and Minds: How We Use Language to Think Together. London: Routledge.

Minick, N. (1987) The development of Vygotsky's thought: An introduction. In R. Rieber and A.S. Carter (eds) The Collected Works of L.S. Vygotsky, Volume 1: The Problems of General Psychology (pp. 17-36). New York: Plenum.

Newman, D., Griffin, P. and Cole, M. (1989) The Construction Zone: Working for Cognitive Change in School. Cambridge: Cambridge University Press.

Renshaw, P.D. (2004) Dialogic teaching, learning and instruction: Theoretical roots and analytical frameworks. In J. van der Linden and P. Renshaw (eds) Dialogic Learning: Shifting Perspectives to Learning, Instruction and Teaching (pp. 87-108). Dordrecht: Kluwer Academic.

Renshaw, P.D. and Brown, R.A.J. (1998) Orchestrating different voices in student talk about infinity: Theoretical and empirical analyses. In C. Kanes, M. Goos and E. Warren (eds) Teaching Mathematics in New Times (Vol. 2, pp. 468-475). Brisbane: Mathematics Education Research Group of Australasia.

Tharp, R.G. and Gallimore, R. (1988) Rousing Minds to Life: Teaching, Learning, and Schooling in Social Context. New York: Cambridge University Press.

Van Oers, B. (1998) From context to contextualizing. Learning and Instruction 8 (6), 473-488.

Van Oers, B. (2001) Educational forms of initiation in mathematical culture. Educational Studies in Mathematics 46, 59-85.

Vygotsky, L (1987) Thinking and speech. In R.W. Rieber and A.S. Carton (eds) The Collected Works of L.S. Vygotsky, Volume 1: Problems of General Psychology. New York: Plenum.

Wegerif, R., Mercer, N. and Dawes, L. (1999) From social interaction to individual reasoning: An empirical investigation of a possible sociocultural model of cognitive development. Learning and Instruction 9 (6), 493-516.

Wegerif, R. and Scrimshaw, P. (1997) Introduction: Computers, talk and learning. In R. Wegerif and P. Scrimshaw (eds) Computers and Talk in the Primary Classroom (pp. 1-18). Clevedon: Multilingual Matters.

Wistedt, I. and Martinsson, M. (1996) Orchestrating a mathematical theme: Eleven-year olds discuss the problem of infinity. Learning and Instruction 6 (2), 173-185.

Zack, V. (1999) Everyday and mathematical language in children's argumentation about proof. Educational Review 51 (2), 129-146.

\section{Appendix}

\section{Transcript 1}

Manuelle: Because they just leave stuff there, take no care, they don't clean, they just [] if you have a toilet in Haiti, you take care of it, it won't have mould.

Sylvio: $\quad$ Children, let me say something. OK, all right, she said that [her toilet] doesn't make mould. You, you said you don't agree. Explain.

Student: Toilets make mould! (Twalet fe limon!)

Manuelle: Not all. (E pa tout.)

Sylvio: How do you explain? (Koman eksplike?) 
Student: [] toilet downstairs has mould. ([] Twalet anba fe limon.)

Student: [] clean it. ([] clean li.)

Manuelle then reclaims the floor.

Manuelle: OK. What I told you, I told you, MY TOILET at MY HOUSE doesn't have mould because I CLEAN it

Student: All toilets have mould. (Tout twalet fe limon.)

Manuelle: Not all. (E pa tout!)

Another student, Marc, after giving Manuelle credit for her claim, proposes to test it with an experiment.

Marc: That makes that, it doesn't have mould, it's because she always washes at her house, if she didn't. We ought to do an experiment. (Sa $k f e s a$, li pa fe limon, e paske li toujou lave lakay li, si li pat. Se pou fe eksperyans.)

Joanne: At home, we usually, Monday, Tuesday, Wednesday, we usually [] clean the bathroom in, if you see where people go to the toilet, it is starting to be yellow inside, then you clean it, when you clean it it's hard to get it all out, you have to (Ballenger, 1997: 5-6) use clorox, [] it's that [] mould begins to appear.

\section{Transcript 2}

Interaction between Visiting Teacher and Lisa

Teacher: What is collective argumentation?

Lisa: Collective argumentation is a form of doing mathematics that's new and probably improved because it not only deals with mathematics, but it gives you lots of different views about, just, problems in everyday life... um...

Teacher: How do you mean? How's that so?

Lisa: Well, in, with maths, um, you represent your ideas individually, you know, the mathematics problem, you know, like Kerri says. You do, you know, you do six steps like (represent, compare, explain, justify, agree, validate). But with the everyday problem, like, um. .. . I don't know, any problem, you think about all the ways, you know, all the aspects of the problem and then you, kind of, do the pros and cons in your mind.

Teacher: Right.

Lisa: And you validate it and you do basically the same six steps, only in a different way.

Teacher: Right, so these six steps provide you with the process for solving any sort of problem in life, you think?

Lisa: Yes.

Teacher: Okay, good.

Teacher: How does collective argumentation differ from other ways of learning mathematics? 
Lisa: Um, there seems to be three general ways of learning, um. One is by hearing it. You hear it and you can repeat it. It's good for like music. The other one is you see it, visual, and you can memorise it. The other is, like, touch, like, you write it (writes in the air with her hands). But with collect. .. , and usually like, it's (classroom learning) just learning by rote, which for most people it's just hearing ability. But the other two abilities of learning aren't used type of thing. It (rote learning) doesn't explore those abilities, it (rote learning) only caters for those who can hear it. But with Collective Argumentation, you can hear it, see and write, just, you know, so you can transform it (the problem) to your own understanding and it helps you to learn the problem easier and to learn it in different ways.

Teacher: What haven't you enjoyed about collective argumentation?

Lisa: Um, the problems ... I know that some people are slower, but it's very difficult when you've only got one problem to solve and, you know, it might be the same type. Like, just say we're doing area. It might be a whole week of area problems, and you get a little sick of just doing area. I think it should be a bit more variety. Like, each day you should keep changing the topic constantly.

Teacher: Are you more aware of the values of collective argumentation when you have a poster displaying them in the classroom?

Lisa: I think the thing that makes us a lot more aware of the values is that we are practicing them everyday. Um, like, with 'teamwork' (one of the values) in collective argumentation, even if you really don't like the person, then you have to do maths with them, and you find that their way of thinking is quite understandable and that they're actually really nice, but you didn't know it.

Teacher: $\quad$ So through this process it's getting people, um ...

Lisa: (Nodding in agreement) It's people skills, yes.

Teacher: Why come to an agreement about one problem solution to be presented to the class?

Lisa: Well, um after you have represented by yourself and you've done the other steps, then you see what everybody else's ideas and aspects are. But what you're aiming for and what is best in High School is the most efficient, mathematical way that you can come up with. So, um, you need to choose the best way so that the class can see that way as well. And it might actually help them through High School, not only with problems surrounding that area, but also with totally different things, like ...

Teacher: So coming to an agreement is an important thing and sharing one solution as a group will help you with other things?

Lisa: Yes.

Teacher: What will you take from collective argumentation with you to High School? 
Lisa: I'd take the knowledge, the values and the steps. Like, because if you are given a maths test and if there was a problem, um, it, you could quickly, um, do the steps, but just on your own and instead of comparing ideas with others, you could just write down another person column and write other ways of doing the problem, just you do it yourself.

Teacher: What do you like about collective argumentation.

Lisa: Ijust would say that collective argumentation is something that I will take with me to High School. I've learnt a lot from it and I hope it spreads to other schools throughout Australia. 